\title{
ETHNOGRAPHY AND THE LAY SCHOLAR IN THE CARIBBEAN
}

BY

\section{ANDREW PeArse}

The founding of a University College in the British West Indies has given rise to serious thinking about the characteristic role of a University in societies such as these, whether in the training of professionals, the development of research, or in its less definite role in the crystallisation, criticism and transmission of current methods in the presentation, discussion, criticism and advocacy of these ideas and values. The Extra Mural Department's programmes of lectures and classes in the different Caribbean territories have been arranged to make the influence of the University felt in this latter sense. Recently the Extra Mural Department, in pursuit of these aims, started a programme of Local Research, the aim of which is the documentation and study by "lay-scholars" of significant aspects of the cultures and social histories of its diverse parts. In particular attention is being directed to folk culture. We feel justified in using the term folk culture since, although it has been shaped and given its functions by the total system of relations between the various sections of our societies, there is a sharp cleavage between the patterns of folk life and the standards emanating from super-structural (i.e. Colonial) institutions.

The Caribbean societies consist of a collection of island and littoral territories between North and South America, which in no sense constitute a socio-economic system. They have similar yet separate and individual relationships to different mother countries, on which they depend socially, economically, politically and culturally.

Nevertheless, on account of the similarity of economic and other relationships to the mother countries, and the interrelated historical development of the latter, they have been subject to the same or to similar historical forces, e.g. they have been colonial societies which developed after

$$
-133-
$$

West-Indische Gids XXXVI 
the destruction of the aboriginal societies; their basic social and economic unit has been the plantation; their labour force has been brought from Africa under the system of slavery; they have responded to the career of sugar-cane in the world market, and they have been subject to the radical transformation of the social structure by legislation, i.e. the emancipation of the slaves etc.

The societies have no traditional peasantry with developed crafts and a system of internal markets and no comprehensively institutionalised traditional structure of community organisation.

All the societies have a superstructure integrated with or derived from the institutions of the mother countries (legal, religious, political and educational, etc) This superstructure consists of administrative machinery, official ecclesiastical organisations, legal systems, large and medium-sized economic concerns, linguistic and aesthetic norms, as well as a complex of prestigeful patterns of behaviour and attitudes, which are represented by an elite,

The life of the populace, mainly of African origin, is partially regulated by the institutions and norms of the superstructure, leaving nevertheless substantial areas of ,,folk culture" the patterns and norms of which are often at variance with those of the superstructure, and the institutions of which have not succeeded in acquiring stability, recognition or effective organisation beyond particular neighbourhoods or islands. This folk culture is differentiated in major respects from that of the superstructure, and in minor respects from one territory to another.

Social ranking systems are closely paralleled by ethnic differences thus serving to exaggerate the split between those who belong to the folk, and are Negro, and those who to a greater or lesser extent are able to identify with the norms of the superstructure, or the mother country itself.

The programme at present being carried out experimentally in the British West Indies is based on the assumption that there are a sufficient number of "lay scholars" in the community who, with guidance, are capable of doing reliable research. In the larger territories this is certainly the case. Particularly amongst the professional and technical occupations are to be found persons with the necessary training and sharpness of mind: with good University Degrees in social science or arts, musicians, draughtsmen, painters, potters, those with legal training, architects, lecturers in Training Colleges, librarians, extension workers etc. who clearly carry a variety of the skills and mental attitudes required for good field work.

Whether or not they can be mobilised, however, depends on the stage of cultural development of the individual society. Until recently the powerfully prevailing attitude of the class from which the lay-scholars come was hostile to any appreciative interest in folk culture, with its lowclass, African, associations. Recent years, however, have produced a new minority attitude within this class in the larger territories, attributable to the growth of Afro- and Indo-national consciousness tinged with racism, to the inanation of former prejudice amongst the better educated of the 
class, to the economic (tourist) value of the more spectacular manifestations of the folk culture, the new voice of the democratic politicians and the interest shown by such high prestige institutions as Universities, both at home and abroad, in popular life. In the smaller territories, the number of such persons is so limited that they do not add up to a group, and therefore remain in ineffective isolation. But in the larger territories they gravitate towards certain organisations and institutions (Museums, dance and drama groups, journals, extra mural research groups and classes) where their views are socially acceptable and their activities are praised and subjected to thoughtful criticism. What remains to be done is to provide technical assistance, expert advice, official recognition, the possibilities of publication and a minimum of organisation.

Hitherto, owing to the diversity of talents and standards, lectures and classes have been little more than stimulants, and a means of association. Development of methods has been done through the planning of madeto-measure projects, within the scope of the individual, followed by discussion of methods, and general supervision.

Projects which have been undertaken by the "lay-scholars" working with the Staff Tutor for Local Studies, and an American anthropologist attached to the programme are:

1 Descriptive Ethnography of Tobago Peasant Life A group of students are working with assistance from Agricultural Extension Officers. It is hoped that the material may be collected by the end of 1955, and published as a book thereafter,

2 Folk Music of the Southern Caribbean A collection of recorded and transcribed music, with about 1,100 items; a selection to be published as a series of Long Play records of each accompanied by a short monograph.

3 Exhibition of Carnival Costumes and Paraphernalia 1954 Given with the co-operation of the Royal Victoria Institute and the Curator of the Museum. Opened by the Minister of Education and visited by 20,000 people. Done by Committee of 5. Repeated on a larger scale, 1955. 23,000 attended.

4 Index of Cultural Materials in Trinidad Newspapers 1820-19oo Card Index of entries referring to cultural development, and social structure in Trinidad by group of 5 .

5 Carnival Studies Monographs on several traditional Carnival Masquerades.

6 Archive of Calypso On tape and manuscript, made by Dan Crowley, with assistance of students, with 560 entries.

7 Big drum Dance of Cariacou A study of the dances, music, words and social function of the festival.

8 St. Lucia (a) Establishment of a depository for oral folklore with the Librarian. (b) Study of popular festivals.

9 Monograph on Building and Launching of a Schooner in Cariacou.

10 Monograph on a type of Traditional Rural House and its use.

11 A manual of 22 Traditional Children's Games of Tobago, with accounts of the games, and musical transcriptions.

Whilst the place of the folk in West Indian society differs radically from that which it occupies in European society, it is interesting to look at in- 
stances of similar types of study by learned institutions there. Probably the most famous and elaborate development is in Sweden.

The Swedish Institute for Folklife (Institutet for Folklivsforskning) established in 1941 is connected to the Nordisk Museet and the University of Stockholm, and supported partly by the Royal Board of Social Research, and is now the key-stone of an important national movement with a history of well over a century - the Hembygdsrorelsen (Movement for the Preservation of Ancient Local Culture). This movement appears to have sprung out of the early 19th century romanticism which inspired in patriotic Swedish scholars and literats an attachment to their native traditions, and which took effect in the founding of small collections of records on their early history and mythology in some of the provincial capitals. Later local antiquarian societies and museums were founded, often by high-school teachers with somewhat dilettanti interests, and by the end of the century this movement became associated with the popular adult education movement on the one hand, and with the spirit of scientific research in the Universities on the other, so that the ethnographer took his place beside the antiquarian.

Since 1942 local societies have been grouped around regional museums, and the state pays a large part of the officials' salaries.

The contribution of this movement to Swedish life is considerable: a. A great mass of archives and artifacts has been systematically assembled by 700 local societies, and several thousand old buildings have been preserved. b. Town and country museums have become a daily part of the education of the young, and are centres of local interest and pride. c. By study, selection and dissemination of this material national life has been able to maintain a singular and distinctive quality through the maintenance and reintroduction of traditional activities and forms which are compatible with modern life, in spite or urbanising influences (e.g. cottage industries, choral songs, social dances, local forms of dress etc.)

The Institute of Folklife carries out its own research projects by field trips and through its 700 correspondents, advises on those of local societies, and conducts university classes. However, publication is its main function, and it collaborates closely with the adult education movement in the dissemination of its publications. In general its researches have a bias towards the minutiae of economic history, and "cultural geography". General studies of individual villages, however, have resulted in a sociological trend. It also uses the study of biographies of individuals as a means of approach to the study of culture and society. Its achievements and its present strength seem to be in part due to the intimate connection between the Universities, the popular educational movements, with their local pride and local museums, and the State. The enthusiastic participation of lay scholars on the one hand, and the continuous process of feeding back to the community the ancient cultural treasures on the other has the two advantages that: it keeps the universities alive in their contact with the community; and it ensures the moral and financial support of state, municipality, parish, commoner and private benefactor alike.

There are certain examples of Extra Mural Departments undertaking local studies projects. MaUrice BARLEY at Nottingham has achieved results in archeological fieldwork and in the study of parish histories. The Departments at Aberystwyth and Birmingham universities have recently 
embarked on a combined survey of the material culture, traditional customs and beliefs of the border countries of Montgomery, Radnor and Shropshire. Though the work will involve "a considerable amount of instruction in cultural anthropology and related subjects, the primary aim (will) be the collection of data rather than education". The investigations are being carried out through adult education classes, schools and women's institutes.

A further recent example can be seen at the School of Scottish Studies, Edinburgh University.

The school, which is two years old, has four research fellows (Celtic Folk, Archeology, Music and Social Anthropology) and expects soon to have its own Director and premises. It is run by a committee on which are represented the Departments of Literature, Languages, Scottish History, Geography, Celtic, Music, Archeology, Fine Art, Scottish Law, Social Anthropology and Phonetics. At present it is much concerned about those aspects of Scottish traditional culture which are rapidly disappearing, hence the bias in the appointment of research fellows.

It is clear that some departments find the activities of the school, with its intrusion into the university structure, more welcome than others. Its purpose was made clear by the Principal, Sir Edward Appleton, when he addressed the first conference called by the school. He described it as (a) an experimental university project cutting across the rigid subject divisions between departments, and therefore demanding of its scholars a new kind of collaboration and open-mindedness. (b) being concerned with the concrete and local it involves field work, thus making new demands on certain types of scholarship which have hitherto been confined to books. (c) the School will amass, sift and evaluate evidences of the traditional culture of Scotland, and will then be able to play a part in disseminating traditional values through the schools, thus helping to form the character of contemporary communities. (d) the contact between the University and the part-time collectors, enthusiasts, and collaborators of all kinds is a most important point at which the University is in touch with the community, providing a deep educational experience to those assisting in the field.

Space does not permit discussion of the Irish Folklore Commission, the Musée des Arts et des Traditions Populaires in Paris, or any of the other interesting examples of such programmes.

\section{APPROACHES TO RESEARCH IN CARIBBEAN FOLK CULTURE}

Reliable research by lay-scholars advised and supervised by experienced scholars requires a certain grading of procedure and methods, and stops short of the more difficult enquiries involving a high degree of abstraction, or a highly complex organisation of empirical data. In the first place, the cultural materials selected for recording or study should be those which are firmly patterned and traditional, clearly defined, and distinct from the larger body of social concourse whose patterns are more recondite, such as:

Oral Literature: Traditional folk-tales, proverbs, riddles, words of songs, prayers, spells, greetings, conventional forms, dramas, secret languages, etc. Legends of old times, of Africa, of slavery, of heroes, vagabonds and liars, of places, of saints, jokes, tell-tales, etc. 
Arts, Crafts, and Techniques: House building, boat building; Pottery, basketry, silver work, re-fabs, etc; Techniques for fishing, hunting, agriculture; Techniques for food preparation and preservation, making of garments, etc; Medical and magical techniques; Making of masks, image painting, building of tadjis, etc.

Music - Musical Instruments: Sung and Instrumental music for work, for secular ceremonies, for cult and religious use, for various kinds of dancing, for social commentary etc., in European, African, East Indian and Spanish Main traditions, as well as essentially Creole music.

Dance: Dress, conventions, programme, style and choreography of the great variety of dances appropriate to different social occasions.

Mime, Play, Pageant: Christmas and Carnival mimes, plays and pageants, involving dressing up, miming, singing and speechmaking, street marches, Saints Day processions, Mummings.

Games: Word games, games with apparatus, singing and dancing games, trials of strength and skill, satirical games, card games, gambling games, team games.

Ceremonies: (a) connected with the life cycle of the individual, from birth, through marriage to death e.g. christening; (b) of the family e.g. "thanksgiving" or "saraka"; (c) of the neighbourhood community school concert; (d) of the society or "bande" etc. e.g. initiation; (e) of an island or "national" society e.g. Fête La Rose, in St. Lucia.

The appropriate types of approach to the material can also be varied in depth from simple collection to complex analysis, for example:

1 COLLECTION OF EASILY ISOLATED ITEMS (WORDS OR ARTIFACTS) WITH A LIMITED AMOUNT OF CONTEXTUAL INFORMATION

Objects, which can be stored or displayed in museums, schools and community buildings, can be collected, along with simple facts about each item, relating to name, age, place and time of acquisition, maker or user etc. Similarly words in set forms or, broadly speaking, oral literature and conventional forms of speech. Since all will be in recognised dialects, approximate spelling is adequate. The superiority of electrical recording in no way undermines the value of collection by interview and transcription. One advantage for the collector is that each act of collecting and registration of information is complete and valuable in itself.

2 GRAPHIC, PHOTOGRAPHIC AND CINEMATOGRAPHIC REPRESENTATIONS OF THINGS, INDIVIDUALS, GROUPS, PLACES, ACTIONS, WITH CONTEXTUAL INFORMATION

3 ELECTRICAL RECORDING OF SOUND, PARTICULARLY MUSIC AND SPEECH WITH CONTEXTUAL INFORMATION

It is possible now to use good portable battery equipment for sound recording, and this makes possible the recording of music and speech in the social or ceremonial setting to which it belongs with fairly high quality. Recording, however, should never be an end in itself, since absence of contextual information detracts greatly from the value of the record. Similarly, as recording is likely to be selective, the material and its surrounding activities should be well known in advance. 


\section{MUSICAL AND CHOREOGRAPHIC TRANSCRIPTION}

Whilst film and sound recording equipment are essential for the study of music and dance, apparatus is not always immediately available, and the writing of musical transcriptions, even if inaccurate is an essential means of identifying items as well as a means of becoming familiar with them. Choreographic notation, however, is much more difficult, and must be left to the specialist. Nevertheless, in order to identify and differentiate dances, it is necessary to attempt graphic (diagramatic or impressionistic) and prose description, which at worst is a useful aide memoire to the researcher.

The four types of activity listed above consist mainly of collection, transcription and mechanical copying. A further valuable form of activity, involving search and selection without description is:

\section{EXCERPTING OF MATERIAL OF CULTURAL INTEREST FROM DOCU MENTA- RY SOURCES}

Whilst the use of archives for the writing of constitutional, political and economic history must be left to the specially equipped historian, the files of old newspapers, reports of enquiries and wills carry a very great deal of material illuminating different aspects of the social structure and culture of these island societies - material conditions of living are richly illustrated, and the social hierarchy seen from above as well as the mainstream of ideological difference in the middle strata. Similarly the "improving" activities, aims, attitudes and methods of the governments, religious and educational organisations and voluntary philanthropic bodies, in their efforts to disseminate Western cultural norms, or else to use these norms as a means of regulating social systems far different from those from which they were derived, are fully displayed. In contrast documentation of folk institutions, of the sub-culture of the Creoles or Indians, Peons or Chinese, of their ways of thinking and learning about the social structure, etc. are much scarcer, and are frequently dismissed as pagan, or vulgar, and in any case unworthy of consideration. Nevertheless, in the detailed reporting of evidence given at Criminal Sessions, or before commissions of enquiry, and occasionally in the writings of less prejudiced, less "culturebound" observers, and the tales of transient travellers, patterns begin to emerge, and these, in view of their source, offer an excellent opportunity for checking the mass of information which relates to the past 120 years and has been passed down, often in a semi-legendary form to people living today.

\section{HISTORIES}

We come now to enquiry, selection and descriptive writing which is based on observation and second hand reports. By histories is meant descriptive accounts of a series of events happening in a particular place, over a certain period of past time. In our case, however, they will be written mainly from oral accounts given by those who have participated in them, and to a lesser extent from observation and from existing records. Whilst it may be possible to cross-check accounts from various people, the knowledge of the field worker of the general environment of the events is a critical factor assisting him only if he can control the attitudes or prejudices which he as a member of the society in question is bound to have. 
The choosing of the subject of a history leads the student face to face with an infinite number of facts, which have no order of priority unless taken from a particular point of view.

The historian of a national state seeks to establish facts from the period under study and their relation to one another as a way of seeking an answer to some question, such as "what helped the development of constitutional government", "was the rising price of bread a main factor in urban discontent" or even "How great was Napoleon?".

Looking at "life histories" written by laymen or students we soon see that they are built around some implicit question such as "How did this poor man become rich?" "Was this man unhappy"? "Why did she turn out so differently from the rest of her family?" and that these unspoken queries operate as criteria for selection of facts. The histories projected as part of the present programme are undertaken to bring out the commonly characteristic features of certain kinds of situations in these societies, or as a way of checking on guesses made previously about the society, seeing the way in which institutions are "used" etc.

Suitable types of "histories" would be:

The history of an individual who moves rapidly up or down the social scale. The history of an association from the point of view of internal conflict, or the type of leaders it has had, and the way they received their leadership. The history of a new settlement of people from the point of view of the mutual relations they enter into to secure common ends, or of a traditional family craft enterprise from the point of view of its adaption to changing economic conditions. Or of a Creole-Indian family from the point of view of the "do's" and "don'ts" applied to its members from two different cultural milieux.

\section{MONOGRAPHS ON MATERIAL OBJECTS ${ }^{1}$}

By this is meant an investigation of physical and social reality contingent on a particular man-made object (and type of object), but is not confined to a single level of thinking. The method recommends itself particularly on educational grounds, since it confronts the student on the threshold of his study with the task of exact observation and description of physical reality, where he is likely to find a far firmer "point d'application" than in trying to handle some of the abstract concepts familiar to social sciences. Similarly the relation between a particular physical object and say, the regional "type" of the object is grasped more safely than for instance the relation between an attitude, expressed in certain words by a particular person, and a pattern or type of attitude which different kinds of people will use different sets of words to express.

The first stage therefore must be the observation and exact description of the selected object, with its raw materials identified and named and its mechanical effectiveness accounted for. This stage leads on to the description of the motor behaviour involved in the process of making and in the use of the object.

1) The monographic method here outlined owes an original debt to Marcel Maget of the Musée des Arts et des Traditions Populaires in Paris. See Guide d'Étude Directe des Comportements Culturels, M. MAGET, Paris 1953. 
The system of material objects, whether made locally in a community or imported, along with the techniques and activities which the making and effective use of these objects demand, lay down for a community one of the basic conditions of daily life, and provide a framework and programme circumscribing other types of behaviour which are less easy to understand and describe.

But having once obtained precise knowledge of a specific object and its associated activities, and the prevailing norms associated with each, it can be used as a "sounding" into the matrix of changing social relations which surrounds it.

\section{Socio-economic Relations surrounding the object}

Transactions in connection with the object involve relationships between individual and group. Raw materials may be acquired with the ownership of land, by purchase or exchange, or the appropriation of recognized waste. Making may be done by paid labour, family group, or in return for rights to use. A work group will have a structure, with some exercise of leadership, and certain types of ceremonial behaviour. Similarly the conditions of disposal and use may be analysed and described.

\section{Place of the object in the Colonial Society}

The making and use of the object involve socio-economic relationships within a household group, a group of kin or associates, and also with the economic, social and political institutions of the colonial society. One way of looking at these relations is to question the extent to which the making and use of the object, and the ends which it serves, are furthered or frustrated by the pressure of the colonial society, working from without or within. The object may lose value because of the importation of cheaper more convenient articles from a large economic enterprise, or it may displace imported articles. Its making, disposal, and use may be subject to a variety of legislation, e.g. Excise, Health Regulations, Taxation, Compulsory Registration and Insurance etc. It may interact with education programmes, i.e. the technique of use may be taught in school, or it may be pronounced undesirable in school. It may conflict with, or be auxiliary to recognised church practices.

\section{The "Meanings" of the object}

Having considered the object first technologically, and next as being the subject of a series of arrangements used in society for handling it as scarce means, it may also be considered as a recognised symbol within the community of some values of a non-economic kind. The object may be associated in people's minds with some aspect of the system of ideas by which they interpret behaviour, and the whole system of social relations. Thus a trash house may symbolise a lowly position in the order of social prestige, whilst the replacement of trash by a galvanised roof symbolises a rise in that order. The wearing by women of white clothes and a white head-tie may symbolise membership of a certain religious sect. The cooking of a dish may be a symbol of recognition of a festival day, and the playing of marbles and the drinking of rum may symbolise the fact of belonging to an age group. A particular object in a special position may symbolise the belief in the presence and availability of supernatural power. 
In cases such as the latter the main purpose of making the object may be its symbolic value rather than its physical ability.

"Meanings" projected into figurative language

Language is rich in words the force of whose meaning is derived from the symbolic meaning associated with the object they connote. Certain objects may have provided language with a treasury of images, used in tales, proverbs, colloquial speech, etc.

\section{Aesthetic Value}

Many objects have "aesthetic value" by which we mean that they are valued as giving pleasure to those who experience them. But the aesthetic component is very hard to identify since it is closely bound up with various symbolic values placed on the object, and when it is much valued it is sought after and thus takes on a high economic value. However it is possible to establish the aesthetic rating given to a variety of objects of the same kind within a community, and thus to generalise certain aesthetic standards for specific types of objects.

\section{Processual Aspects}

In moving from the study of particular and unique objects to that of norms, that is, ideal reconstructions possessing characteristic features of a category of objects, we discover that these norms vary from place to place and from time to time. These temporal and spatial variations should be studied together since the change in any object witnessed in one particular place is (in the West Indies) most often due to the arrival of people or models from another place where a different norm prevails.

Our first concern is with changes in the form and substances of the material object. The Means of Making the object may have changed. These are: 1. The raw materials and tools. Certain substances may no longer be available. and substitutes with different physical properties may have taken their place; more convenient tools may have become available. 2 . The technique and skill. There may have been a failure in the transmission or passing on of the skill from the older to the younger generation, or it may have been modified by becoming institutionalised as a subject of instruction at school. On the other hand, while the means may still be available, the Ends or purpose of making and using may have changed, and thus changed the object. This may happen (1) at the technological level, for example, the object may now be used to perform new mechanical tasks in the structural system to which it belongs. The supporting joints of a roof may now have to carry the heavier weight of galvanised iron sheets instead of light timite-palm thatch, and the pirogue may have to be built to withstand the new strain of being outboard-motor driven. This may happen (2) at the socio-economic level; that is to say, its function in the system of socio-economic relations may change. It may now be made for sale and not for use, and be subject to simplification in the interests of economy. Finally, (3) the symbolic value attributed to the object may have changed. It may have acquired value as the symbol of the self assertion of an ethnic minority; it may have lost its sacred value and gained as a source of aesthetic satisfaction; or its value as a symbol of prestige ranking may have been displaced by the higher prestige of imported goods. 
The above is a classification of the inter-related causes of change in form operating through the awareness of the maker, and taking effect as a result of his choice, his conscious adaption. Behind these causes, and not necessarily conceived clearly by the maker are the major societal convulsions and trends, the most significant and changeful of which is the steady penetration of the community by the products of modern industry.

Facts useful in the study of the process of change in form can be derived from the scrutiny of contemporary objects, processes and attitudes. In the initial study of the given object and its contemporary relation to the system of technology, socio-economic relations and symbolic and aesthetic values, it will appear that there are strong and weak structural elements, i.e., certain operations in making and using are mandatory and must be strongly maintained, whilst others appear to be permissive, and possibly matters of indifference or uncertainty. Contemporary scrutiny of this kind will certainly indicate points at which change is in process or can be expected to take place, since the indifference of the maker will provide little resistance to the various influences for change. Close acquaintance with the maker and his family, sensitive as he is to local pressures, aspirations, age-group conflicts etc. will be still further indicative.

Old objects, the date and place of whose making is known, can be examined and compared with contemporary examples for structural differences.

Oral accounts of past practices can be obtained from people living today, either from their own observation, or from what was told to them. These accounts are often highly subjective.

Drawings, photos and prose accounts of the making, form or function of objects at some time and place in the past.

The culture areas from which the "ancestors" of material objects have come to the Caribbean are several, namely: Western Europe, Africa, India, Indonesia and China - in addition to the Caribbean area itself, whose indigenous inhabitants were Amerindian. In addition there has been ceaseless communication of locally differentiated norms from territory to territory. Therefore facts should be assembled pertaining to (a) norms existing in territories other than the one under study, and at different times, and (b) the varying importance at different times of different channels of communication, migration and exchange of goods.

Further study of the material could, of course, follow several directions i.e. that of the student of social history, and of the process of acculturation or those of the students of the separate aspects of cultures, i.e. language or literature, music, technique, etc.

\section{MONOGRAPHS ON CEREMONIES, ETC.}

The monographic method can be applied not only to material objects but to complexes of actions and objects which are subject to emphatic patterning conventions, and approximate to prevailing current norms in the given geographical or social area. For instance, within our area, the meeting of a political committee or group, though it might follow some sort of pattern of procedure, would, in its most significant and causallyimportant aspects, function as a critical step in the organisation of power relations in response to some new set of events, and should therefore be treated historically. 
But, also the ceremonies, rites, formal festivities, traditional masquerades and dance sequences with which we are familiar are suitable to the method. It is of the character of traditionally patterned events of social concourse that they facilitate co-ordinated and synchronised action by a group of people, and act as symbols or outward expressions of socially accepted values, and as such are sometimes maintained in a degree of relative stability, even in the face of considerable social change. Therefore they may be taken as a whole, and understood in the context of the social relations surrounding them, the meanings they communicate, and the process of change which they undergo in counter-point with general social process. But specific difficulties emerge from the fact that each has diverse internal components differentially subject to modification, and interacting with one another; and because of the fictional nature of its internal relations, i.e. objects, roles and actions look like counterparts in the real world, but may (in extreme cases) be in inverse relation to them (e.g. the clown is a sad man in real life, etc.)

\section{The Components}

Before approaching the ensemble, it is well to observe, list and describe the place, people and things. The item may be located on a road as a procession, moving across significant boundaries between communities; or in a public place or private, in a tent, chapel or "yard" shared between several related families. The exact placing may be regulated by custom, and according to the points of the compass. The lay-out can also indicate the importance given to spectators - a crucial matter since form will change as an event becomes increasingly spectator, or audience, directed - of the same social lovel, or for visitors of higher rank. Thero may be an embryonic or well-developed stage.

\section{The Programme}

Having enumerated the components, the next step is to describe the procedure or action involving the elements in a spatio-temporal programme, along with preparations, making of apparatus and any initial rites or purification or dedication, rehearsals etc. For the event itself, several observers may be needed on account of simultaneous events.

\section{The Legend}

The external phenomena thus described are not dictated by the logic of technique or by other utilitarian principle, but they are supported and unified by a "charter" or "legend" which all participants agree to accept. It is this which gives explicit and immediate meaning to the actions and things and their ordering, and it is accepted as binding: 1 . because it is believed to be sanctioned or commanded by supernatural powers, 2 . because of shared respect for a tradition, and the values which it expresses, 3. because it serves as an effective framework for ordered competition in prowess, or for aesthetic enjoyment and expressive or creative activity.

The legend is likely to specify the roles of the personages and the course of their actions, and it will be enunciated by some leader or organiser. It must be compared with actual performance for significant discrepancies. In addition to the legend there may be a parablewise meaning i.e. the actions executing the legend may be regarded as having a moral. 


\section{The total Event}

The total event consists of components having an internal relationship to one another which are in certain respects isolated systems in their own right. Dance, music and speech in particular are highly formalised. Other internal components are the objects, costumes, rites and other stylised movements, character roles and legends. Furthermore there may be considerable permissive areas of uncharted activity, e,g, the incursions of capricious and unpredictable spirit forces, openings for individual improvisation and creative variation, and virtuosity which overflows the form. The relative importance of the various components, their interaction and conflict needs detailed study. (For example, what are the mutual relations between words, music and movement (i) when the purpose is the intensification of rhythm to induce "possession"? (ii) to amuse an audience with verbal sallies? and (iii) to time and encourage physical labour in unison ?)

The cultural significance of the total event is not likely to be derived either from its direct utility or from the socio-economic relations of which it would be the centre as a "scarce means" or object of exchange. Nevertheless, many of its elements are of this order. Goods and services must be acquired by purchase or other mutuality, and the organisation of contributions amongst the group members is revealing from many points of view. High expenditure on Xmas festivities, Carnival Bands, Weddings and Funeral Rites shows the importance attached to them. The economic position and social rank, family interconnections, religious allegiance and neighbourhood status of the membership should be learnt. The correlation of the fictional roles and those of real life, and the status of the event viz-a-viz the colonial society are all important.

Finally, in studying the way norms of formal social concourse change we must do without old models still in existence. But the conflict of internal elements will be revealing, though complex, since their development is paralleled and influenced by their counterparts external to the event; at one extreme, a new style of dancing may develop externally, and replace the old component of the event; and at the other extreme, the language of daily intercourse may change, yet the old language of the song component may remain, and be sung by people who no longer even understand it. Beyond this, the same type of data is relevant to the process of change as with the norm of a material object.

Of the methods suggested, the first five are comparatively simple; the sixth, histories; involves selection and synthetic description, but is confined to observable events, selected on the basis of more abstract generalised concepts. In the monographic method, we are suggesting a procedure which uses a technological description of an aspect of observable reality as a sounding into the complex depths of society so that when its context is further described at different levels, the data can lead to reliable conclusions about social and economic relationships in primary groups, neighbourhood and nations, about the distribution of norms, and about the process of cultural and social change. The somewhat detailed treatment accorded to 
this method does not pretend to be immediately applicable, but should provide the lines for the construction of correct schedules for specific studies. Nor is it suggested that this method is essentially superior to other approaches to ensemble studies which might be suitable for lay-scholars.

The foregoing has been written out of experience in a small group of five island societies in the Southeast Caribbean, - but would seem to be applicable to most of the other island and littoral territories of the region, and probably to many regions beyond it, where the same or similar basic elements and cultural needs are to be found.

For the fruitful development of such studies we must first look for the growth of centres in individual territories or groups of territories, attached to libraries, cultural centres, university departments, museums, folk-lore societies etc., which can make possible the systematic preservation of the materials, initiation of collection and investigations, and the presentation of the materials for the benefit of interested students, those who plan educational programmes, initiate cultural change, and are themselves engaged in creative work. Further more, the best results can be obtained only if there is contact, exchange of views and materials and some co-operative planning, between the territories, thus overcoming the separateness which has hitherto been imposed by distance, language, and the dependence of the territories on four different metropolitan countries. Only thus can we hope that the extraordinary wealth and diversity of what we tentatively might call "Caribbean culture" can be represented. Trinidad, May, 1955

DE LEEK ALS VOLKENKUNDIG ONDERZOEKER IN HET CARAI̋BISCH GEBIED

Dr ANDRew Pearse, tot voor kort hoofd van de dochter-afdeling in Trinidad van het ,University College of the West Indies" (gevestigd in Jamaica), geeft in dit artikel een overzicht van de mogelijkheden om plaatselijke krachten in te schakelen bij volkenkundige onderzoekingen zoals deze door het University College worden gestimuleerd.

In het Caraïbische gebied, zo goed als elders in jonge staten, ontbreekt nog een grote, geschoolde middenklasse. Volkshogescholen en andere instellingen voor volksontwikkeling in Europa worden door dr PEARSE als voorbeeld aangehaald voor een werkwijze welke ook in West-Indië zou kunnen worden gevolgd. Op grond van zijn ervaring in Trinidad suggereert hij een aantal onderwerpen voor plaatselijk onderzoek en een methode om de belangstelling voor eigen cultuur te ontwikkelen: De leek als onderzoeker kan veel bijdragen door het verzamelen van materiaal in zijn naaste omgeving dat als basis kan dienen voor verdere wetenschappelijke studie.

RED. 